\title{
AN EUALUATION OF SELECTED MOROCCAN ELT TEXTBOOKS: A STANDARDS-BASED APPROACH PERSPECTIVE
}

\author{
Hassan Ait Bouzid \\ Chouaib Doukkali University, El Jadida, Morocco \\ hassan.aitbouzid@gmail.com
}

First received: 8 February 2017

Final Proof Received: 30 May 2017

\begin{abstract}
Standards-Based Approach to textbook evaluation has been blooming in recent decades. Nevertheless, this practice has received very little attention in Morocco. The present study aims to bridge a gap in the literature of the Moroccan context by investigating the extent to which three locally designed ELT textbooks conform to the theoretical principles of the Standards-Based Approach which defines the teaching of English as a foreign language in the country (Ministry of National Education, 2007). Its objective is to examine whether and how these textbooks present contents that enable learners to meet the content standards included in the goal areas of Communications, Cultures, Connections and Comparisons. The study is informed by the theoretical framework of the Standards-Based Approach. It adopts a mixed-methods design that uses content analysis as a mixed data analysis method combining both quantitative and qualitative techniques. The findings reveal a number of shortcomings relevant to the representation of the content standards as several standards are not sufficiently addressed in the activities included in these textbooks. Eventually, some suggestions are addressed to policy makers, textbook designers and teachers to overcome the identified problems in current and future textbooks. The study is expected to sensitize ELT practitioners about the viability of using textbook evaluation in boosting both the quality of ELT textbooks and the quality of the teaching learning outcomes.
\end{abstract}

Keywords: textbook evaluation; EFL; standards-based approach; Morocco

The teaching of English as a foreign language in Moroccan public high school, according to the Ministry of National Education [MNE] (2007), is informed by the theoretical framework of StandardsBased Approach [SBA] (American Council on the Teaching of Foreign Languages [ACFL] 1996). English language teaching in Morocco, therefore, revolves around the promotion of five goal areas: Communication, Cultures, Connections, Comparisons and Communities. These 5C's, according to the MNE (2007), implicitly describe the major components of the teaching and learning of English in Moroccan public high schools. They present the overall content standards that any English language learner must strive to meet to graduate from high school. First, meeting standards of the goal area of Communication enables learners to communicate in spoken and written forms, present information both oral and written and interpret spoken or written messages in a way that takes into account the pragmatic and sociolinguistic factors that affect communication. The standards under the goal area of Cultures further help learners to function in culturally appropriate way by deepening their knowledge about the cultural perspectives, practices and products of both local and foreign communities. Moreover, culture-related standards enable learners to understand differences and similarities between their own culture and the target culture(s) and instill universal values of tolerance and coexistence within cultural equality.
The goal area of Connections contains standards that establish a strong relationship between English and other school subjects because the English language allows not only reinforcing knowledge that learners obtain from other school subjects but also presents a body of knowledge that can only be accessible through this language including the English history, literature, lifestyle, and body of thought.

The fourth goal area, Comparisons, contains standards that aim at fostering the learners' awareness of differences and similarities between their own language and culture and the language and culture being studied. By encouraging students to compare and contrast their language and culture with the target language and culture, they gain more insight into the nature of their own language and culture and create an opportunity for a better understanding of other foreign languages and cultures. The last goal area presents standards that promote lifelong learning and relate the English language classroom experiences with the real world and the future of the learner. The objective of the goal area of Communities is to engage learners in language learning experiences that would not only develop their sense of belonging to a local and a global community of the English language speakers but also enable them to be ready to delve into the life-long experience of continuous learning that is by no means confined by the walls of English language classroom. This, of course, can only be achieved by engaging learners in activities that 
foster their autonomy (e.g. project-based learning and cooperative learning). In general, the ultimate objective of these five goal areas is to train learners to effectively function in a multi-cultural global community of English language speakers while at the same time preserving their local identity as foreign language speakers.

MNE (2007) highlights the importance of having clear, straightforward and well-articulated standards as "they provide learners with the opportunity to acquire the knowledge, attitudes, skills and strategies for better English language learning" (p7). The document further emphasizes the role that teachers are to play if such standards are to be effectively attained. It also presents a detailed discussion of lesson planning to help both teachers and students meet the intended standards effectively. However, the document devotes little room to the teaching materials that are to be used to meet the standards. Apart from scarcely stating that textbook designers should not lose sight of the content standards while designing textbooks, the document offers very little insight into the nature of these textbooks as it does not provide enough guidelines concerning the design of these textbooks.

SBA considers textbooks an instrumental material that facilitates the teaching learning process. They are viewed as tools that enable learners to meet the standards if textbooks are appropriately designed. To this end, textbooks should be conceived with reference to content standards so that they present what teachers should teach and what students should learn appropriately. MNE (2007) entices textbook designers to "have the five standards areas referred to earlier in mind" while designing textbooks; putting thus all emphasis on content standards. The belief that both teachers and students need to have a clear idea about the lessons to be learned during the whole school year is one of the reasons why content standards are prioritized with regard to textbook design (American Council on the Teaching of Foreign Languages [ACTFL], 1996; Jibreel, 2015; Wiggings $\&$ McTinghe, 2005).

Because textbooks are not perfect as they may contain various instances of bias related to various issues, the investigation of their pedagogical import is of primordial importance. The primeval role of ELT textbooks is to present a language content in the most appropriate and suitable method that enables learners to improve their linguistic competence; it is therefore an essential task for textbook evaluators to investigate the degree to which the textbooks being used to mediate the teaching-learning process satisfy the needs of the learners, teachers and curriculum. Textbooks have to cater for the learners' needs, interests and expectations to develop their foreign language competence. Also, they have to meet the teachers' expectations in terms of facilitating the teaching task and helping them to guide students through their learning experiences. More importantly, textbooks need to take into consideration the objectives of the curriculum and provide content that assists the attainment of these objectives in a way that is comprehensible both to the teachers and to the learners. Therefore, the evaluation of ELT textbook should be concerned with investigating whether and how textbooks align with the pedagogical principles that underlie the theoretical framework of the curriculum.

The investigation of the pedagogical content of ELT textbooks is becoming a central issue in textbook evaluation studies in recent years as several researchers have expressed their intriguing interest in this domain. Cisar (2000) designed a standards-based textbook evaluation guide in the form of a checklist that included 31 criteria which align with the five goal areas of the SBA to foreign language education. The methodology consisted in mainly browsing parts of the textbook and its ancillaries for activities that addressed each of the eleven standards contained in the five goal areas of Communication, Cultures, Connections, Comparisons and Communities. The findings demonstrated that the textbook contained more activities that addressed the standards of the goal areas of Communication and Cultures than those addressing the standards of the goal areas of Connections and Comparisons. Activities addressing standards of the goal area of Communities were obviously allotted little room (Ait Bouzid, 2016).

In the same view, Indiana Department of Education (2007) developed a standards-based textbooks evaluation guide that allows educators to evaluate foreign language teaching textbooks using the ACTFL standards. The evaluation form consists of six major sections including the five goal areas of Communication, Cultures, Connections, Comparisons and Communities in addition to a general-elements section that evaluates the four skills, objectives and suitability of the textbook. To use the evaluation guide effectively, one has to examine the textbooks using the provided list consisting of 66 criteria followed by rating and scoring operations. The scores are then counted and compared with scores of other textbooks to determine which one is more suitable to be used in the intended teaching-learning context. It is worth noticing that the evaluation guide was essentially designed to facilitate the textbook selection process.

Despite the fact that the criteria included in these checklists are rigorous and to a great extent comprehensive, this textbook evaluation method is only suitable for the purpose of evaluation for selection. It does not provide concrete evidence that would explain and justify the scores. The scores do not help in improving the quality of the content of the textbooks as much as they basically include or exclude a textbook in or from the list of materials to 
be used. Yet, the criteria included in these evaluation forms or checklists can easily be adapted to the diverse purposes of different textbook evaluators (Laabidi \& Nfissi, 2016).

Alemi and Mesbah (2013) investigated the extent to which two internationally distributed textbooks used in Iranian EFL context were in harmony with the principles of the SBA using Cisar's (2000) checklist. The findings revealed that the textbooks were successful in dealing with the majority of content standards except for the two standards under the goal area of communities. The researchers claimed that the textbooks did not provide enough activities that could enhance learners' autonomy and develop a sense of life-long learning.

Kazem and Fatemeh (2014) and Aniroh (2014) evaluated an English language teaching textbook used in the teaching of students of dentistry in Iran. The first researchers adapted an evaluation checklist based on standards of the ACTFL Evaluation Checklist. Their findings indicated that the textbooks did not meet the requirements of the eleven standards of the five Cs, while Aniroh (2014) concluded that obtaining a high score does not entail that the textbook is necessarily effective or appropriate; only continuous evaluation could maintain textbooks in their satisfactory level.

Alemi, Jahangard and Hasemi (2013) and Sarem, Hamediand and Mahmoudie (2013) examined the diversity and suitability of tasks in two widely used international ELT textbooks in Iranian EFL institutes. The researchers relied on Nunan's (1999) classification of tasks to identify different types of tasks included in the textbooks. Tasks were identified and classified into five categories: cognitive, interpersonal, linguistic, affective and creative. A statistical content analysis method was adopted to count the frequency of each task category. The results of this study pointed out that these textbooks predominantly comprised linguistic and cooperative tasks but marginalized cognitive and practice ones.

Alamri (2008) and Phonhan, Praphan and Chaiyasuk (2012) investigated the extent to which three textbooks used in the teaching of English as a foreign language in Saudi Arabia and Thailand were consistent with principles of the content based instruction (CBI) adopted by the teachers in their teaching practices. Their evaluations relied on a teachers' questionnaire designed through adapting criteria of different checklists found in the literature. The data was analyzed both qualitatively and quantitatively. The findings of the two studies, also similar to Ahour, Bayezid and Mahnaz (2014), revealed that teachers were to a great extent satisfied with the textbooks as they mostly helped them to meet the objectives of the course by using authentic materials and combining different teaching methods alongside CBI. Nevertheless, Saudi teachers complained that the textbook they used did not adopt modern teaching methods and that the activities it comprises were not student-centered. By contrast, Ashari and Zarin's (2014) investigation of the extent to which select Iranian EFL textbook succeeded in meeting the objectives of the communicative approach to which they claimed to pertain concluded that the textbooks were concerned more with reading than with other skills. Also, the content of the textbooks was mostly non-authentic and consisted of topics that failed to meet the teachers' expectations. It seemed that the textbooks used did not succeed in developing the learners' communicative competence as they claimed.

The aforementioned studies stressed the importance of evaluating the pedagogical import of EFL textbooks. An in-depth analysis of the pedagogical content of these textbooks is crucial in determining the extent to which they fulfill the requirements of the curriculum and achieve the objectives of the course. To heighten the quality of the teaching learning outcomes, the reviewed body of literature highlighted the centrality of conducting an effective analysis of the pedagogical content of the textbooks in terms of authenticity of the teaching objectives, the teachability of the contents and its appropriateness to the learners along with its accordance with the theoretical framework and methodological guidelines that underlie the curriculum with special reference to the SBA which constitutes the core of the present study. Eventually, according to Ait bouzid, Erguig and Yeou (2016), an effective, systematic and reflective evaluation of these contents informs teachers, textbook designers and educational policy makers about potential problems and suggests ways in which these problems can be currently overcome and possibly avoided in future textbooks.

The present study aims to investigate the extent to which three Moroccan ELT textbooks currently used in teaching second year Baccalaureate students in public high schools conform to the pedagogical principles of SBA as illustrated in official guidelines of MNE (2007) and the American Council on the Teaching of Foreign Languages [henceforth ACTFL] (1996). The objective is to examine the extent to which these textbooks present contents that enable students to meet the requirements of the eleven content standards included in the five goal areas of Communications, Cultures, Connections and Comparisons. Ultimately, the study hopes to draw the attention of ELT practitioners to the viability of using textbook evaluation as a means to improve the quality of textbooks and eventually enhance the quality of the teaching-learning outcomes. Two main research questions drive the present study:

1. To what extent do selected Moroccan ELT textbooks present contents that align with the 
pedagogical requirements of the StandardsBased Approach?

2. How do these textbooks enable learners to meet the eleven content standards included in the goal areas of Communications, Cultures, Connections and Comparisons?

\section{METHOD}

The study adopted a mixed-methods design using content analysis as a mixed data analysis method that combines both quantitative and qualitative techniques (Krippendorff, 2004). The objective is to evaluate the content of three Moroccan ELT textbooks currently used in teaching second year Baccalaureate students in public schools.

\section{Materials}

The present study examines three main ELT textbooks currently used in Moroccan public high schools: (1) Gateway to English 2 (Hassim, Blibil \& Rasmy, 2007), (2) Insights into English 2 (Najbi \& El Haddad, 2007), and (3) Ticket to English 2 (Hammani, Ahssen \& Tansaoui, 2007). These textbooks are locally designed and are considered as national textbooks that are used interchangeably to teach the final level in Moroccan public high schools.

\section{Data Analysis Procedures}

The three textbooks were analyzed both quantitatively and qualitatively to examine the extent to which they align with the pedagogical principles of SBA. The purpose of the quantitative analysis is to identify whether the number of these activities is sufficient for promoting the eleven content standards included in four goal areas of SBA and whether the number of activities is distributed equally among the different goal areas so that no content standard is undermined. The purpose of the qualitative analysis is to identify the kind of activities that are used in promoting the different content standards and the quality of the presentation of the instructions. The quantitative analysis consisted of making frequency counts of activities that provided texts, dialogues and exercises whose aim is to teach any of the 9 content standards and illustrating them in tables. Each table was followed by a descriptive qualitative analysis which describes ways in which different activities are used to promote these standards. The interpretation of both quantitative and qualitative data is fused with the qualitative description that follows each table since it is impossible to separate qualitative analysis from interpretation according to Cohen, Manion and Morrison (2007).

\section{FINDINGS AND DISCUSSION}

\section{The Goal Area of Communications}

Table 1 reveals that $50.8 \%$ of communicative activities in Gateway to English 2 are devoted to promoting the interpretive mode, while $29.4 \%$ of these activities target the presentational mode; interpersonal communication is given only $19.8 \%$ of these activities. Similarly, $55.8 \%$ of communication activities located in Insights into English 2 promote interpretive skills of reading and listening, while $26 \%$ of communication activities aim to foster interpersonal skills of face-to-face communication; $18.2 \%$ of communication activities are actually designed to foster the presentational communication skills of speaking and writing to an audience. In the same token, $57.2 \%$ of communication activities identified in Ticket to English 2 are devoted to promoting interpretive communication skills (reading and listening), while face-to-face communication constitutes $29.1 \%$ and the presentational activities including speaking and writing make only $13.7 \%$.

Table 1. Number of activities devoted to the goal area of Communication

\begin{tabular}{llllllllll}
\hline & & \multicolumn{2}{c}{ Gateway 2 } & \multicolumn{2}{c}{ Insights 2 } & \multicolumn{2}{c}{ Ticket 2 } & \multicolumn{2}{c}{ Total } \\
\hline Interpersonal mode & Face-to-face & 55 & $19.8 \%$ & 43 & $26 \%$ & 51 & $29.1 \%$ & 149 & $24.2 \%$ \\
& & & & & & & & & \\
\hline Interpretive & Reading & 101 & $36.4 \%$ & 74 & $44.8 \%$ & 68 & $38.9 \%$ & 243 & $39.3 \%$ \\
\cline { 2 - 10 } Mode & Listening & 40 & $14.4 \%$ & 18 & $11 \%$ & 32 & $18.3 \%$ & 90 & $14.5 \%$ \\
\hline $\begin{array}{l}\text { Presentational } \\
\text { Mode }\end{array}$ & Speaking & 63 & $22.6 \%$ & 14 & $8.5 \%$ & 6 & $3.4 \%$ & 83 & $13.4 \%$ \\
\hline Total & Writing & 19 & $6.8 \%$ & 16 & $9.7 \%$ & 18 & $10.3 \%$ & 53 & $8.6 \%$ \\
\hline
\end{tabular}

It is generally observed that the three textbooks do not present the three modes of communication equally nor do they provide activities that develop the three standards included in the goal area of Communication in a balanced manner. The three textbooks present a great number of activities that ask learners to read texts, dialogues and sets of sentences to help them develop good reading skills. Similarly, listening activities included in these textbooks provide learners with opportunities to listen to people speaking different varieties of English offering students a chance to familiarize themselves with various accents from Nigeria, Australia, England, USA, Canada, Egypt, Morocco, China and Korea. They also encourage learners to engage in interpersonal communication activities that promote face-to-face communication skills through encouraging students to engage in 
conversations, roles plays, dialogues, discussions, making comparisons, making explanations, justifying choices and answering questions revolving around different topics and in different situations and contexts. However, none of the three textbooks contains activities in which students would listen for fun such as listening to songs although songs are a good means of promoting the learning of the language and the culture of the target language community. It is also noticed that these textbooks do not contain a sufficient number of activities that promote presentational communication skills. Actually, few activities encourage learners to present their ideas, feelings and opinions orally to an audience of listeners. In addition, they contain a small number of speaking activities that entice learners to share, present and/or report their findings, ideas, feelings and opinions with their peers in the classroom. Also, it is observed that, despite the scarcity of the writing activities (less than 2 writing activities per unit), the three textbooks contain a variety of writing tasks that encourage students to write different types of texts including stories, reports, application letters, formal and informal e-mails and letters as well as argumentative essays. However, the writing tasks identified in these textbooks are all accuracy-based because they are all guided by checklists; free writing activities that are fluency-based are not included in these textbooks.

\section{The Goal Area of Cultures}

Table 2 indicates that the three textbooks contain 62 activities that fall within the realm of the goal area of Cultures. 33 of these activities aim at boosting students' understanding of the relationship between perspectives and practices of the cultures being studied while 29 activities aim to enable learners to understand the relationship between perspectives and products of these cultures. The table also reveals that the three textbooks contain approximately the same number of activities intended for the goal area of Cultures. Ticket to English 2 contains the highest number of such activities (22 activities), Gateway to English 2 contains 21 and Insights into English 2 contains 19 activities. It is also noted that Ticket to English 2 presents the highest number of activities fostering understanding of the relationship between cultural perspectives and cultural practices of both foreign and local cultures while Insights into English 2 contains 11 and Gateway to English 2 contains only 10 activities.

However, Gateway to English 2 comprises the highest number of activities (11 activities) aiming at promoting learners' understanding of the relationship between cultural perspectives and cultural products of the foreign and local cultures being studied as compared with Ticket to English 2, which contains 10 similar activities and Insights into English 2 which features only 8 activities.

Table 2. Number of activities promoting standards of the goal area of Cultures

\begin{tabular}{lcccc}
\hline Standards & Gateway 2 & Insight 2 & Ticket 2 & Total \\
\hline $\begin{array}{l}\text { Understand links btw } \\
\text { perspectives \& practices }\end{array}$ & 10 & 11 & 12 & 33 \\
$\begin{array}{l}\text { Understand links btw } \\
\text { perspectives \& product } \\
\quad \text { Total }\end{array}$ & 11 & 8 & 10 & 29 \\
$\quad$ & 21 & 19 & 22 & 62
\end{tabular}

Generally, it is observed that the three textbooks provide activities that enable learners to understand the relationship among different cultural perspectives and cultural practices. For instance, the three textbooks provide instances of ways in which different forms of education enable people from different cultures to function in their respective societies. They also provide insights into how different cultures perform various types of celebrations and art. In addition, these textbooks offer different perspectives on how sustainable development is approached in various cultural contexts and provide several ways in which international organizations influence the lives of different countries. Moreover, they present instances of how problems of brain drain, gender inequalities, illiteracy and lack of political involvement affect both communities of foreign and local cultures. On the other hand, the three textbooks provide learners with opportunities to understand the relationship between cultural perspectives and cultural products. For instance, the textbooks contain several activities that inform learners about proverbs, jokes, riddles, idioms, organizations, articles from various constitutions, foods, manners, films and works of arts. However, it is noticed that these activities mostly revolve around the 'what' and 'how' as they merely present what people do and how they do it while actually ignoring to raise the questions of 'why they do what they do in that particular manner.' In order for student to fully understand cultural differences, they need to know the reasons or factors that determine these cultural practices and products. For instance, in order for learners to understand specific celebrations, they need to know their origins and the cultural context that defines them including history, religion, attitudes and relationships. In this regard, the three textbooks do not provide answers to the question 'why' but merely present the cultural practice or product and state how it is done or how it is used; therefore, students' understanding of the relationship between cultural perspectives, practices and products remains to a great extent 
incomplete as these activities do not enable them to understand the 'why' of the culture.

\section{The Goal Area of Connections}

The results in Table 3 indicate that the three textbooks contain 208 activities that promote standards of the goal area of Connections, 111 of which establish connections with other subjects, while 97 provide students with information and viewpoints that can only be accessed through the study of English language and its culture. They also reveal that Gateway to English 2 contains the lowest number of activities (58 activities) among the three textbooks, while Insights into English 2 contains the highest number of activities (76 activities) with a minimal difference as compared with Ticket to English 2 which contains 74 activities. The table additionally shows that the three textbooks include a higher number of activities dealing with the first standard of making connections with other subjects than those targeting the second standard of providing information and viewpoints that could only be accessed through the study of English language and its culture although the difference between these standards does not exceed 2 activities in Gateway to English 2, 6 activities in Insights into English 2 and 4 activities in Ticket to English 2.

Table 3. Number of activities promoting the standards of the goal area of connections

\begin{tabular}{lcccc}
\hline Standards & Gateway 2 & Insights 2 & Ticket 2 & Total \\
\hline Connection to other subjects & $30(51.7 \%)$ & $40(52.6 \%)$ & $41(55.4 \%)$ & $111(53.3 \%)$ \\
Access information \& viewpoints & $28(48.3 \%)$ & $36(47.4 \%)$ & $33(44.6 \%)$ & $97(46.7 \%)$ \\
Total & $58(100 \%)$ & $76(100 \%)$ & $74(100 \%)$ & $208(100 \%)$
\end{tabular}

It is observed that the three textbooks present various activities that establish connections with different subjects in an attempt to enable learners to reinforce their knowledge of other subjects through the study of English language. Table 4 illustrates this diversity in more detail.

Table 4. Types of subjects connected with English

\begin{tabular}{|c|c|c|c|c|}
\hline & Gateway 2 & Insights 2 & Ticket 2 & Total \\
\hline Anthropology & 2 & 2 & 3 & 7 \\
\hline Civic education & 1 & 3 & 1 & 5 \\
\hline Computing & 2 & 2 & 2 & 6 \\
\hline Economy & 3 & 4 & 5 & 12 \\
\hline Geography & 1 & 2 & 3 & 6 \\
\hline History & 4 & 4 & 5 & 13 \\
\hline Journalism & 2 & 4 & 2 & 8 \\
\hline Languages & 3 & 2 & 2 & 7 \\
\hline Literature & 3 & 3 & 5 & 11 \\
\hline Law & 1 & 2 & 1 & 4 \\
\hline Mathematics & 1 & 1 & 2 & 4 \\
\hline Medicine & 1 & 2 & 1 & 4 \\
\hline Philosophy & 2 & 2 & 2 & 6 \\
\hline Physics, chemistry \& biology & 2 & 4 & 5 & 11 \\
\hline Sociology & 2 & 3 & 2 & 7 \\
\hline TOTAL & 30 & 40 & 41 & 111 \\
\hline
\end{tabular}

Table 4 shows that the three textbooks contain activities that make connections with 15 subjects. It is noticed that activities establishing connections with history, economy, literature, science and journalism make $49.5 \%$ of the connections identified in these textbooks, while activities connecting English with mathematics, law and medicine are scarce as they constitute only $10.8 \%$ of the identified activities. The table also indicates that activities establishing connections with subjects that interest students of the experimental sciences stream such as computing, economy, mathematics medicine and sciences (biology, chemistry and physics) constitute $33.3 \%$ of activities included in this table, while activities relevant to students of arts and human sciences (including literature, languages, history, philosophy, anthropology, sociology, law and journalism) form $62.1 \%$ of the total number of these activities. In addition to activities fostering connections between English and single subjects illustrated in Table 4, a number of activities contained in these textbooks establish connections with multiple subjects at a time. For instance, the three textbooks present a number of activities which provide learners with study skills and effective learning strategies that are essentially useful in all school subjects such as note-taking skills, using SQ5R, preparing for exams, strategies for building vocabulary, mind-mapping, brainstorming, conducting surveys, effective questioning, using dictionaries, making a Powerpoint presentation, organizing and outlining ideas.

On the other hand, the three textbooks provide a set of activities that introduce learners to information and viewpoints that could only be accessed through the use of English language. For instance, a number of activities provide learners 
with information about foreign cultural perspectives, practices and products that can be reached and understood only through the use of the English language. For instance, the textbooks offer insights into a number of celebrations, traditions, attitudes, life-styles, manners, jokes, poems, songs, riddles, organizations, attitudes, ideas, and facts about different countries including, though not limited to, England, USA, China, India, Korea, Japan, Nigeria, Dominican, Canada, Peru and Argentina. However, it is noticed that the amount of information textbooks present concerning English-speaking African countries is very limited. In general, the three textbooks succeed in providing a sufficient number of activities that connect English with a number of school subjects. They also succeed in presenting activities that inform students about cultural aspects of various cultures. However, it is noteworthy that the three textbooks do not contain activities that connect the English language classroom with Islamic education, Arabic and French. Connections with these three subjects are ignored due to the scarcity of religious content in these textbooks and the shortage of activities that entice learners to compare and contrast the English language with the first and second languages of the learners as indicated in the section below.

\section{The Goal Area of Comparisons}

Table 5 demonstrates that the three textbooks do not present the two content standards of goal area of Comparisons in the same manner. It shows that only Insights into English 2 presents activities that actually address the two standards, while neither Gateway to English 2 nor Ticket to English 2 include content that entices learners to establish comparisons among different aspects of local and foreign languages. Gateway to English 2 and Ticket to English 2 contain 7 activities each that enable students to make comparisons between different aspects of local and foreign cultures, as compared with 20 similar activities in Insights into English 2. The latter textbook presents 4 activities that encourage learners to make informed comparisons regarding local and foreign languages, while the other two textbooks contain none.

Table 5: Number of activities promoting standards of the goal area of Comparisons

\begin{tabular}{cccc}
\hline & Gateway 2 & Insights 2 & Ticket 2 \\
\hline Comparing cultures & 7 & 20 & 7 \\
\hline Comparing languages & 0 & 4 & 0 \\
\hline
\end{tabular}

It is observed that Insights into English 2 devotes a special section to activities promoting the standards of the goal area of Comparisons: 'Compare it'. Ticket to English 2 includes similar activities in the section of 'Explore culture', which is usually located at the last page of the Unit, while Gateway to English 2 does not provide a special section for Comparisons, but rather includes them in post-reading and post-listening activities. Presumably, including comparative activities within reading and listening lessons guarantees more chances for students to engage in these comparisons through their personal reactions to the listening or reading texts than actually placing them at the end of the unit as a supplementary or secondary activity that learners only do if they have some time left. Nevertheless, including a heading that introduces these activities as comparisons helps the learners understand the purpose of such activities.

The three textbooks use different types of activities to promote the goal area of Comparisons. Gateway to English 2, for instance, presents three activities allowing learners to compare culturally appropriate and inappropriate behaviors among western and local cultures. It also provides an activity that addresses the issue of youth's engagement in politics and an activity comparing the role of Moroccan schools in promoting good citizenship as well as an activity that asks learners to identify push and pull factors behind brain drain in Morocco. Ticket to English 2 contains several activities aiming at establishing comparisons among different local and foreign cultural components such as comparing famous gifted people, famous humorists, literacy statistics, the role of NGOs in promoting sustainable development, table manners and attitudes towards the United Nations. Insights into English 2 presents various activities which compare different elements of foreign and local cultural perspectives (including attitudes and feminism), practices (gift giving and complaining about faulty goods), products (including jokes, proverbs, films, slogans, and constitutional articles). The latter textbook also contains a number of activities that compare languages of foreign and local cultures through asking leaners to identify the types of language used while talking about brain drain in their mother tongue, asking them to provide examples of jokes in their mother tongue and finding expressions that are used in expressing partial agreement in their mother tongue.

The findings of the analysis of pedagogical issues reveal that the three textbooks do not present content that enable students to meet the 11 content standards included in the goal areas of Communications, Cultures, Connections, Comparisons and Communities. In fact, the three textbooks do not represent the eleven standards in a balanced way that has the potential of promoting students' learning and attainment of these standards as dictated by MNE (2007) and ACTFL (1996).

The three standards included in the goal area 
of Communications are presented insufficiently throughout the three textbooks. These textbooks provide content that targets the promotion of the interpretive mode of communication more than they do for the interpersonal and the presentational modes. Also the textbooks prioritize reading skills and marginalize writing skills as indicated by Ashari and Zarin's (2014), Cisar (2000) and the Indiana Department of Education (2007). In addition, the listening activities included in these textbooks are not totally authentic as they do not include examples of songs to which students are more likely to listen. Therefore, it could be concluded that the goal area of Communications is presented in a crippled way that promotes interpretive and interpersonal modes and marginalizes the presentational mode. In line with Kazem and Fatemeh (2014) and Aniroh (2014), it could be argued that the three textbooks do not succeed in promoting the three standards of the goal area of Communications equally and effectively.

Additionally, the way foreign and local cultures are represented in these textbooks does not allow for developing the competencies and skills needed for meeting the requirements of the two standards included in the goal area of Cultures (Cisar, 2000; Cunningsworth, 1995). The three textbooks do not present content that could foster students' understanding of the relationship between diverse cultural perspectives and cultural practices because of over-emphasizing cultural perspectives and practices relevant to schooling and economy. It is also observed that the three textbooks do not include a variety of content that could foster learners' understanding of the ways in which cultural perspectives and cultural products are interrelated. For instance, the shortage of religious content does not allow textbooks to function as cultural mediators that have the potential of explaining cultural differences which mainly originate from the religious differences; therefore, they do not contribute to alleviating religious antagonism and radicalism (Ait Bouzid, 2016). In general, the way textbooks present standards of the goal area of Cultures is to a great extent nonauthentic and incomprehensive since they do not represent the diversity of cultural perspectives, practices and products of both foreign and local cultures as indicated by Ashari and Zarin's (2014).

Contrary to the claims of Ashari and Zarin's (2014), Kazem and Fatemeh (2014) and Aniroh (2014) the three textbooks succeed in presenting contents that promote the two standards included in the goal area of Connections equally. It is observed that textbooks actually provide a wide variety of activities that establish connections with various school subjects, thus meeting the requirements of the first standard contained in the goal area of Connections. The textbooks also succeed in presenting a sufficient number of activities that target the second standard of the goal area of
Connections as they allow learners to access information and viewpoints that could only be obtained through the use of English as a foreign language. However, the problem of variety and authenticity persist since these activities are not as diverse because the amount of information and viewpoints that are contained in these textbooks are not as varied as the English speaking community is; they mainly focus on providing information and viewpoints of the Anglo-American community. Also, the authenticity of these pieces of information and viewpoints is oftentimes at risk since various problems related to stereotypes and biased representations are often identified in various activities promoting the second standard of the goal area of Connections.

Concerning the goal area of Comparisons, the three textbooks do not provide enough activities that promote both standards it includes. Although the three textbooks provide a number of activities that promote comparing foreign and local cultures, it is observed that not all aspects of cultural perspectives, practices and products are juxtaposed and contrasted. Cultural comparisons identified in these textbooks provide visual, textual and contextual contents that do not reveal the cultural diversity that marks both foreign and local cultures. These textbooks do not present examples of the subcultures that form the mosaic nature of both local and foreign cultures. It is also noted that the three textbooks present foreign culture and local culture at an unequal status through presenting the foreign culture as superior to the local culture. In addition, it is noticed that the textbooks do not encourage comparing local and foreign languages since they include very few activities that require students to compare and contrast English with their own languages. In general, the second standard included in the goal area of Comparisons is highly undermined.

\section{CONCLUSION}

This paper has presented an evaluation of pedagogical issues in three Moroccan ELT textbooks including Gateway to English 2, Insights into English 2 and Ticket to English 2. It consists of five main sections that have respectively presented findings of the quantitative and qualitative analyses of the extent to which these textbooks present activities that foster the content standards included in the goal areas of Communications, Cultures, Connections and Comparisons. Findings have revealed a number of strengths and weaknesses related to both quantity and quality of the contents that aim at meeting these standards. Also, ways in which each content standard has been presented throughout the three textbooks are discussed and several instances of imbalanced representations are revealed. Generally, it is concluded that, despite 
claiming to adhere to the theoretical framework of the Standards-Based Approach as plainly suggested by the guidelines of the $\operatorname{MNE}(2007)$, the three textbooks do not fully abide by the recommendations of both the official guidelines (MNE, 2007) and the Standards-Based Approach (ACTFL, 1996).

The present study concludes with several implications in the form of suggestions addressed to ELT practitioners and educational policy makers in Morocco. First, policy makers should encourage ELT practitioners to engage in the practice of textbook evaluation. Also, they should encourage researchers, teachers and textbook designers to conduct yearly evaluations of the contents of textbooks. Second, textbook designers should take into account the principles of the theoretical framework of English language teaching adopted by the policy makers in designing future textbooks. In addition, they should design textbooks that include more activities that encourage making comparisons between local and foreign languages. Third, teachers should design activities and extra-materials that contain activities fostering the undermined content standards. Examples of activities that teachers may use to compensate for the shortcomings identified in the three textbooks include:

a. Authentic listening activities to cater for the shortage of listening activities in textbooks;

b. Listening activities featuring different accents including Asian and African English speaking communities to illustrate the nature of English as an international lingua franca;

c. Listening and reading activities featuring perspectives, practices and products of English speaking communities other than British or American ones;

d. Discussions that touch upon religious and philosophical perspectives that define practices and products of foreign and local communities,

e. Quick-writing activities to cater for the shortage of writing activities in textbooks;

f. Translation activities to cater for the lack of activities of comparing languages.

\section{ACKNOWLEDGEMENTS}

I would like to express my gratitude to Dr. Reddad Erguig and Dr. Mohamed Yeou for their insightful comments and formative feedback on this paper. Special thanks are also addressed to anonymous reviewers.

\section{REFERENCES}

Ahour, T., Bayezid, T. \& Mahnaz, S. (2014). The evaluation of English textbook 2 taught in
Iranian high schools from teachers' perspectives. English language Teaching, 7(3), 150-158.

Ait Bouzid, H. (2016). Boosting $21^{\text {st }}$ century skills through Moroccan ELT textbooks. Journal of English language teaching and linguistics, 1(2), 97-108.

Ait Bouzid, H., Erguig, R. \& Yeou, M. (2016). Towards a reflective textbook evaluation model. EFL Journal, 1(3), 219-233.

Alamri, A. A. (2008). An evaluation of the sixth grade English language textbook for Saudi boys' schools. Retrieved from http://faculty.ksu.edu.sa/amri/Documents/MA $\% 20$ thesis.pdf.

Alemi, M. \& Mesbah, Z. (2013). Textbook evaluation based on the ACTFL standards: The case of Top Notch series. Iranian EFL Journal, 9(1), 162- 179.

Alemi, M., Jahangard, A., \& Hesami, Z. (2013). A comparison of two global ELT course books in terms of their task types. IARTEM e-Journal, 5(2), 42-63.

American Council on the Teaching of Foreign Languages. (1996). Standards for foreign language learning: preparing for the 21st century. Alexandria: Author.

Aniroh, K. (2014). Evaluation of a hotel management textbook based on world language standards. Bahasa \& Sastra, 14(2), 131- 152.

Ashari, N. \& Zarrin, N. (2014). Problems in using communicative language teaching in Iran and possible solutions. Technical Journal of Engineering and Applied Sciences, 4(4), $257-$ 266.

Cisar, S.H. (2000). Standards-based textbook evaluation guide. Bloomington: Indiana University.

Cohen, L., Manion, L. \& Morrison, K. (2007). Research methods in education. London: Routledge.

Cunningsworth, A. (1995). Choosing your Coursebook. Oxford: Macmillan Education.

Hassim, M., Blibil, M. \& Rasmy, A. (2007). Gateway to English 2. Rabat: Nadia Edition.

Hammani, M., Ahssen, S. \& Tansaoui, L. (2007). Ticket to English students' book. Casablanca: D.I.O. El Hadita.

Indiana Department of Education. (2007). Standards-based textbook evaluation guide. Retrieved December 23, 2007 from http://www.doe.state.in.us

Jibreel, I. (2015). Evaluating Blue Skies 6 with reference to Yemeni students. Arab World English Journal, 6(2), 372 -384.

Kazem, B. \& Fatemeh, H. (2014). Evaluation of an EAP textbook: English for the students of dentistry. Merit Research Journal of Education and Review, 4(2), 062-076. 
Krippendorff, K. (2004). Content Analysis: An introduction to it methodology. London: Sage Publications.

Laabidi, H. \& Nfissi, A. (2016). Fundamental criteria for effective textbook evaluation. Journal of EFL, Linguistics and literature, 1(2), 141-159.

Ministry of National Education. (2007). English language guidelines for secondary schools: Common core, first year, and second year baccalaureate. Rabat: Author.

Najbi, M. \& El Haddad, E. (2007). Insights into English 2. Rabat: Al Massar Edition.

Phonhan, P., Praphan, W. \& Chalyasuk, I. (2012). An evaluation of my world textbooks regarding the EFL teachers' perceptions and classroom applications. A case study of Thai teachers. RMU.J (Humanities and Social Sciences), 6(2), 17-28.

Sarem, N. S. Hamedi, H. \& Mahmoudie, R. (2013). A critical look at textbook evaluation: A case study of evaluating an ESP coursebook: English for international tourism. International Research Journal of Applied and Basic Sciences, 4(2), 372-380.

Wiggins, G.P. \& McTinghe, J. (2005). Understanding by design. Alexandria: Association for Supervision and Curriculum Development. 